\title{
Virtue: An Indispensable Factor That Guarantees the Effects of Engineering Education
}

\section{- - Teachings from Confucius Said ${ }^{*}$}

\author{
Yingjie Guo \\ School of Foreign Languages, Shaanxi Normal University, Xi'an 710062, China \\ guoyingjie@snnu.edu.cn
}

\begin{abstract}
By referring to Confucius Said, the paper holds that virtue is an indispensable factor that guarantees the effects of engineering education. As for its significance in engineering education, virtue displays itself both as a "foundation" and as a "destination". Regarding its roles in engineering education, virtue respectively serves as a key to promise the responsibility of teachers, a facilitator to ensure the capability of students, and a channel to foresee the harmonious environment of schools. Relating to the suggestions of implementing virtue in engineering education, the paper holds that until we communicate with virtue, virtue is here with us; only through bearing the responsibility of various social beings can virtue have its glory; with the reasonable participation of mercy, virtue can do contributions to our nation and society. Besides, "respect, forgiveness, trustworthiness, diligence, and generosity" are the "five things" to characterize engineering education with perfect virtues. China.

Index Terms - Virtue, Engineering education, Confucius Said,
\end{abstract}

\section{Introduction}

Chinese Academy of Engineering ever made a survey, finding that "obsolescent thoughts, out-dated styles, stale approaches" as well as "antiquated knowledge and dissatisfactory abilities" are the very reasons that hinder the fast development of Chinese Engineering[1]. Reading between the lines, we may unconsciously think of engineering education and consider that it is engineering education that deserves to be blamed[2], though virtually a variety of social factors function together and account for these disadvantages. Essentially, the qualified establishment of engineering education is one of the great desires Chinese people cherish all along whereas we know that "Rome is not built one day" and engineering education should follow its own unique way, otherwise the accomplished jobs may go astray. Considering these facts, all of us have the responsibility to do contributions to the bright future of engineering education, and it will be a holy cause that requires our patience, commitment and determination. Personally, by observing the teachings of Confucius Said[3], I believe that virtue is an indispensable factor that guarantees the effects of engineering education. Yet fundamentally, we need to have a consideration and maybe reconsideration of the value of virtue in engineering education.
According to Random House Webster's College Dictionary, virtue concerns not only "conformity of one's life and conduct to moral and ethical principles", but also "rectitude" and "effective force, power or potency"[4]. Longman Dictionary of Contemporary English, on the other hand, emphasizes the "moral goodness of character and behavior", associates "a particular good quality in someone's character", and implies "an advantage that makes something better or more useful than something else"[5]. Obviously, virtue is of great significance in engineering education and plays important roles through the specific fulfillments of engineering teachers, students and schools.

\section{Significance of Virtue in Engineering Education}

\section{A. A Foundation of Engineering Education}

It is an acknowledged truth that without virtue, without the promising future of engineering education, lying in the fact that virtue is a foundation of engineering education. On the one hand, engineering education is one of the reflections of "the applications or realizations of the intentions of engineers"[1], which employs virtue as an essential characteristic and the original force. Virtue prepares potential opportunities for would-be engineers to become superior men because virtue demonstrates the reasoning spirits that engineers desire. On the other hand, engineering education, as a particular form of human education through "the practical application of science and mathematics"[1,4], aims to foster talents who can fill themselves with wisdom and virtue. Confucius says that "Only a person of virtue is able to enjoy a virtuous life, and only a person of wisdom is able to benefit a virtuous life."[3] If engineering talents attempt to change themselves into the capable engineers in the future, virtue is a sound answer, especially in the struggling and sometimes frustrating atmosphere of engineering realities. Therefore, if engineering education is a splendid mansion we can see and touch, virtue is the solid and unshakable base to start its budding form and assure its amazing magnificence.

\section{B. A Destination of Engineering Education}

Engineering education, without any doubt, exists not only with the theoretical demands as its objectives, but also with the

\footnotetext{
* This work is partially supported by Innovation Funds of Graduate Programs(2013CXB013), SNNU; 2013 Visiting Scholar Exchange Program, SNNU; and the social science research programs attached to Shaanxi Province (08K005) and Ministry of Education of China (GPA 105004, 10YJA752031).
} 
practical demands as its destination, which means that qualified engineers are the needs of people[2]. However, how can we define engineers qualified? Apart from capabilities, intelligence and wisdom, virtue will be necessarily considered because virtue is a destination of engineering education. Firstly, engineering education intends to witness the growth of the would-be engineers who immerge themselves with virtuous thoughts. As is known to all that engineers with wisdom yet lack of virtue are less capable than those who have virtue yet lack of wisdom. Secondly, engineering education inclines to embrace the meaningful practice resulted from virtue or characterized with virtue. We know that engineering education is fundamentally available for the interests of our nation, which shows that the peaceful advancement of engineering education demands the participation of virtue and the fulfillment of virtue. Last but not least, Virtue is a crucial element that engineering education needs and develops while virtue is also a highlighting quality that engineering education wishes for and rests on[6]. Briefly, virtue is a destination that engineering education strives for.

\section{Roles of Virtue in Engineering Education}

\section{A. A Key to Promise the Responsibility of Teachers}

Confucius says that "A person should not be concerned about nobody knowing him. He should be concerned about not knowing others."[3] In engineering education, teachers occupy important positions and they are those unsung heroes who exert unseen effects upon engineering students. Indeed, they are like the lighting candles and the silkworms that sacrifice themselves for a holy purpose. However, engineering education is, as we can observe, basically a job of conscience. How can we guarantee the quality of the engineering teaching in the long run? Engineering teachers have ineluctable responsibility. Yet how can these teachers bear their responsibilities? One of the vital keys is their virtue or morality. Virtue makes engineering teachers different because they behave as they should be. Moreover, virtue directs engineering teachers to have fair thoughts and proper styles to influence their students, as Confucius comments again, "Only a man of virtue knows how to use the proper way to like a person or dislike a person"[3]. The point here is that engineering teachers set models to their students because of virtue and the students will follow suit under the guide of virtue afterwards, which seems sustainable.

\section{B. A Facilitator to Ensure the Capability of Students}

Virtue is transparently a facilitator in engineering students' life, which will ensure their capabilities, either in academic studies or in social communications. To start with, virtue may shape engineering students' characters with good intentions. Even when they meet frustrations or difficulties, virtue can help them suit moral and ethical principles as superior men usually behave in routine life. Confucius says that "If a man decides to be a man of virtue, he will not do evil things"[3] In the second place, virtue may make engineering students have self-supervision and let them cultivate their talents voluntarily. No students originally like to fall behind, especially when they fill themselves with aspirations, strength and hopes. Thirdly, virtue provides possibilities for engineering students to do good to our nation and society. Students have unbound creative ideas, innovating powers as well as potential abilities. Hence, developing their qualities properly is an issue under heated discussion. But one thing is certain, "If a superior man abandons virtue, how can he still be called a superior man?"[3,7].

\section{A Channel to Foresee the Harmonious Environment of Schools}

Virtue plays a particular role in engineering schools because virtue is a channel to foresee whether the school environment is harmonious or not, or the harmonious school environment is satisfactory or not. On the one hand, virtue is one of the characteristic reflections of the harmonious school environment. It is known to us that "in practicing the rules of propriety, harmony is the most important"[3]. To make engineering schools well-organized and to have engineering education well-performed, virtue must be highlighted. On the other hand, virtue is a distinctive label to characterize the harmony of engineering schools, which can both stimulate the charm of their reputation and attract the attention of society and enterprises. At least, engineering schools exist for the needs of society and enterprises. If engineering schools start from virtue, go along with the demands of society and develop with the requirements of enterprises, their prosperity will be under way. "In doing so, morality in society will be increased.”[3]

\section{Suggestions of Implementing Virtue in Engineering Education}

\section{A. Virtue is here!"}

Confucius says that "Is virtue a thing remote? When I want to be virtuous, virtue is here!"[3] Through learning this philosophy, we, initially, cannot take it for granted that virtue is too abstract to believe or it is too far away from us to maintain in engineering education. Thus, we had better avoid the prejudices about virtue as well as the poor attitudes towards it. To some extent, it is improper to assume that virtue is the mere conduct of superior men-"Since I do not want be a superior man, I show no interest in virtue!" To some degree, adjusting our thoughts and correcting our attitudes are more important than expecting the results of virtue itself. Moreover, "actions speak louder than words." It is true that "a virtuous man always speaks virtuous words; however, a man who speaks virtuous words is not always a virtuous man."[3] Actions of virtue are the best answers and until we perform with virtue and communicate with virtue, virtue is definitely here with us.

\section{B. Let "responsibility" Act}

In engineering education, "responsibility" does not simply mean that of engineering teachers or students, nor does it merely mean the "responsibility" of engineering schools. It 
means the responsibility of the whole society. Only through bringing into play the responsibility of all social beings can virtue have its glory and grandness. Namely, virtue is the responsibility of every learned one who should put it into practice and have effects in real life. "His responsibility is heavy and long. His responsibility is to carry out virtue."[3] In addition, to make engineering education fully successful and essentially qualified, we cannot only focus on engineering science itself. In other words, we ought to involve the participations of other disciplines. The world today is international and communicative, and we cannot live blindly in a small sphere of pure engineering science. We need the winwin cooperation of multiple scientific disciplines like Material Science, Automation Science, Manufacturing Science, Biological Science, Medical Science, etc., which can and will guarantee the effects of engineering education.

\section{C. "The word is MERCY"}

Confucius says that "The word is MERCY. It means that whatever you do not want to be done to you, do not do it to others." [3] In engineering education, we should make full use of the knowledge we have obtained from school and try to work out the effective ways to do contributions to the development of our nation and society, which is "mercy" and a demonstration of virtue. Otherwise, if we misuse our knowledge, concern the material wealth only and forget who we are, the engineering education will move towards a wrong direction and be a total failure, which is not a symbol of "mercy"; on the contrary, it is a disaster, both scientifically and ethically. Hence, "If a scholar only thinks of the comforts of (his own) life, he should not be called a (good) scholar."[3] In today's world that has dangling attractions, it is easy to do a "favor" or have "mercy" once, but it is difficult to "repay the favor with favor" all the time[3]. Even so, we wish to find as many superior men as possible, not only from engineering education but also from present "us". "If a man can be righteous in his actions, perform everything according to the rules of propriety, speak with humility, and carry out the things he has promised, such a man is a superior man."[3] Obviously, mercy and virtue should be considered together.

\section{D. "Five things" should go along}

"Perfect virtue is being able to carry out five things wherever one goes." Specifically, "virtue" here includes the ingredients of "respect, forgiveness, trustworthiness, diligence, and generosity"[3]. In engineering education, "respect" does not only mean respecting teachers, engineers or academic authorities, it also implies respecting engineering science, moral principles, natural rules and social orders as well. "Forgiveness" is a way to pardon oneself or others when he/she or they commit(s) mistakes while in engineering education, forgiveness stands for the chances or occasions that we can improve the abilities or renew the thoughts, especially in unexpected frustrations and difficulties. Yet forgiveness does not mean giving up. "Trustworthiness" may harvest friendship. Yet more practically, it can strengthen our learning and enlarge our eyesight when we get access to the latest knowledge and the newest discoveries at home and abroad. We peculiarly trust the knowledge that has been examined by practice and facts[6,7]. "Diligence" shows that we have to be down-to-earth and earnest in engineering studies and realistic work, which requires us to learn not only from our charming past and beaming traditions, but also from interdisciplinary advantages and overseas exemplifications that prove successful and adequate. "Generosity" intends to clarify that we are happy to share with others our successful endeavors and achievements. So to speak, we do not want to confine ourselves in a narcissistic world and instead we are inclined to communicate with any one or group who yearns for engineering knowledge, either in China or in other countries. However, generosity does not mean that we "give" without principles and limits[8].

\section{Summary}

Teachings from Confucius Said prove to be valuable. Referring to Confucius Said, as far as we can see here, virtue is an indispensable factor that guarantees the effects of engineering education. As for the significance of virtue in engineering education, we can claim that it is a "foundation" as well as a "destination". Regarding the roles of virtue in engineering education, we can observe that virtue respectively serves as a key to promise the responsibility of teachers, a facilitator to ensure the capability of students, and a channel to foresee the harmonious environment of schools. Relating to the suggestions of implementing virtue in engineering education, we hold that until we communicate with virtue, virtue is here with us; only through bringing into play various social beings can virtue have its glory; with the reasonable use of knowledge and participation of mercy, virtue can do good to our nation and society. Besides, "respect, forgiveness, trustworthiness, diligence, and generosity" are the "five things" to characterize engineering education with perfect virtues.

\section{Acknowledgment}

This work is partially supported by Innovation Funds of Graduate Programs(2013CXB013), SNNU; 2013 Visiting Scholar Exchange Program, SNNU; and the social science research programs attached to Shaanxi Province (08K005) and Ministry of Education of China (GPA 105004, 10YJA752031).

\section{References}

[1] D.Q. Lu, "Researches on quality control in engineering specialties and construction of quality control system in electronic engineering majors," Journal of UESTC, vol. 7, supplement, pp.24-26, June 2005.

[2] L.Y. Cao, "Reflections on the innovation education of institutes for mechanical engineering majors," Science \& Technology Information, vol. 13, p.161, July 2011.

[3] D.W. Ma, Confucius Said, Shanghai: Shanghai World Book Press, 2004, pp. $3,14,6,18,15,71,5,32,48,34,57,47,51,54,64$.

[4] Random House Webster's College Dictionary, New York: Random House, 1999, p. 124. 
[5] Longman Dictionary of Contemporary English, Beijing: Foreign Language Teaching and Research Press, 2012, p. 2218.

[6] J. H. Zhou, "A method on teaching reform of production practice in mechanical engineering major," Modern Educational Technology, vol. 19, no. 7, pp. 135-137, April 2009.

[7] Y. H. Gu, X. J. Cai and X. H. Liu, "A study of the teaching plans of University of Minnesota for mechanical engineering undergraduates," Higher Science Education, vol. 85, no. 3, pp. 67-71, February 2009.
[8] S. J. Wang, Y. Y. Wang and L. X. Wang, "Exploration and practice of cultivating university students' engineering abilities and innovation spirits," Experimental Technology and Management, vol. 22, no. 2, pp. 9-13, January 2002. 